Research Article

\title{
Compartment pressure changes after closed fractures of tibia
}

\author{
Manju G. Pillai* \\ Department of Orthopaedics, Pushpagiri Institute of Medical Sciences and Research Centre, Thiruvalla, Kerala, India
}

Received: 15 August 2016

Accepted: 29 August 2016

*Correspondence:

Dr. Manju G. Pillai,

E-mail: drmanjukannan@gmail.com

Copyright: (C) the author(s), publisher and licensee Medip Academy. This is an open-access article distributed under the terms of the Creative Commons Attribution Non-Commercial License, which permits unrestricted non-commercial use, distribution, and reproduction in any medium, provided the original work is properly cited.

\begin{abstract}
Background: Compartment syndrome is a potentially devastating situation. Raised intracompartmental pressure has been implicated as the primary pathogenic factor in compartment syndrome. The purpose of the study was early detection of compartment syndrome and corroborating the findings with other physical signs and symptoms, to prevent the onset of ischaemia and subsequent tissue changes that lead to crippling deformities.

Methods: The present study was conducted in the Department of Orthopaedics, Pushpagiri medical college hospital, Thiruvalla over a period of 12 months. Closed fractures of tibia admitted to the casualty unit within 36 hours of injury were selected for the study. A total of 24 patients were included with the majority in the age group of $31-45$ years. Whitesides technique was used to measure the compartment pressure. A differential pressure of less than 30 $\mathrm{mm} \mathrm{Hg}$ was taken as the criterion for diagnosis of compartment syndrome.

Results: The present study included 24 patients with affected 25 limbs.15 out of 25 limbs were with lower third fractures (60\%) followed by upper third $6(24 \%)$ and middle third $4(16 \%)$. Out of 25 limbs 20 cases $(80 \%)$ had associated fracture of fibula and $5(20 \%)$ were not associated. In this study, out of $32 \%$ cases with increased compartment pressure, one case with upper third fracture (above $45 \mathrm{~mm} \mathrm{Hg}$ ) and one of the case with middle third fracture $(20-30 \mathrm{~mm} \mathrm{Hg})$ with associated fibula had underwent immediate fasciotomy.

Conclusions: Compartment pressure measurement is a very good index for predicting and preventing compartment syndrome. Fasciotomy to fully decompress all involved compartments is the definitive treatment for compartment syndrome in the great majority of cases. Delays in performing fasciotomy increase morbidity.
\end{abstract}

Keywords: Ischemic contracture, Compartment syndrome, Closed fractures, Pressure changes

\section{INTRODUCTION}

Ischaemic contractures are well known complications of limb bones with serious motor and sensory functional implications in the affected limb. ${ }^{1}$ This may lead to development of compartment syndrome in lower limbs. It is a potentially serious complication following a tibia fracture. The rates of ACS with tibia fractures ranges from $2 \%$ to $9 \% .^{2-4}$ It occurs when there is any elevation in interstitial pressure in a closed osteofascial compartment. This raise in pressure leads to decreased blood flow, nutrient and oxygen supply to the affected tissue. If resultant ischaemic damage was not reversed within six hours it can result in long-term morbidity and even death of muscle tissue.
The most sensitive clinical symptom of compartment syndrome is severe pain. A fasciotomy should be performed when the difference between compartment pressure and diastolic blood pressure is less than 30 mmHg.

The incidence of compartment syndromes following tibial fractures was majorily due to motorcycle accidents. $^{6}$ To diagnose the compartment syndrome invasive measurement is a quick and safer procedure described by Whitesides et al. But now-a- days continuous pressure monitoring devices are commercially available. ${ }^{8}$ Hence, direct monitoring of the compartment pressure changes in all suspected cases is the single 
dependable diagnostic tool for the early detection of impending ischaemia.

The present study aimed at early detection of compartment syndrome by routine monitoring of the pressure changes within the various osteofascial compartments of the leg during the first 48 hours of injury (closed fractures of tibia) and corroborating the findings with other physical signs and symptoms, impending ischaemia that can be detected early, and prompt measures that can be taken to prevent the onset of ischaemia and subsequent tissue changes that lead to crippling deformities.

\section{METHODS}

The present study was conducted in the Department of Orthopaedics, Pushpagiri Medical College and Hospital, Thiruvalla over a period of 12 months. Closed fractures of tibia admitted to the casualty unit within 36 hours of injury were selected for the study. Cases admitted after 36 hours of injury were excluded from the study because of increased chances of infection and unpredictable effect of decompression even if compartment pressure is high. Informed consent was taken from each patient. 24 patients were included in the study after meeting the inclusion criteria. There were 20 male and 4 female patients with the majority in the age group of 31-45 years. The standard values for the various compartments in uninjured limbs were first ascertained.

Clinical evaluation of the general condition of the patient was made with special emphasis to his/her diastolic blood pressure. A detailed clinical evaluation of the injuries was carried out as per proforma appended. The fractures are confirmed by radiological examination. The tissue pressure of all the four compartment were measured and recorded. The fracture is then reduced by closed manipulation and immobilised in plaster of Paris slab.

The measurement is repeated after 6-8 hours and recorded. The appearance of other physical signs and symptoms were observed. In all suspected cases pressure monitoring and physical examination repeated at shorter intervals. If the pressure changes indicate impending ischaemia, it was confirmed by other methods like Doppler studies and fasciotomy was carried out in all proven cases.

In the present study Whitesides technique was used to measure the compartment pressure as the equipment was easy to set up, the procedure is simple, interpretation of results direct and chances of errors less as shown in Figure $1 .^{7}$ The principle in this method was measuring the compartment pressure by adjusting the syringe, a small quantity of saline was introduced into the compartment to be measured, so that this saline is in continuity with the tissue fluid of the compartment. This pressure is directly read from the manometer, which is in direct continuity with pressure within the saline column and the air column in the syringe.

Whitesides' technique employs the following materials i) Sphygmomanometer - Mercury type, ii) one three-way stopcock, iii) One $20 \mathrm{cc}$ syringe, iv) Two 18 gauge needles, v), Two plastic intravenous extension tubes vi) One bottle of sterile normal saline vii) Link adapters of polyethylene to connect the extension tubes to the threeway stopcock and to the other components. The extremity to be measured is cleaned and sterility prepped. Sterile saline is drawn into the $20 \mathrm{ml}$ syringe, which is attached to the three-way stopcock. A single intravenous extension tube is attached to the stopcock and a second 18 gauge needle is attached to its other end. The third unused portion of the stopcock is closed off temporarily. The 18 gauge needle at the end of the extension tube attached to the stopcock is then inserted into the bottle of the saline. Saline is then aspirated without the bubbles into approximately half the length of the extension tube. The three-way stopcock is turned to close off this tube so that the saline is not lost during transfer of the needle. The second extension tube is then connected to the three-way stopcock at its remaining open part and its other end is connected to the manometer. The saline-containing needle is then inserted into the muscle of the extremity to be tested. The stopcock is then turned so that the syringe is opened to both extension tubes, forming a Tconnection with a free column of air extending from behind the column of saline into the syringe as well as into the manometer. Pressure is increased in the system gradually by slowly depressing the plunger of the syringe while watching the column of saline. As the plunger is depressed, the saline meniscus will be altered from a convex configuration to a flat configuration, when the air pressure in the system equals the interstitial pressure in the patient's examined tissue. The manometer reading at this time is the tissue pressure in $\mathrm{mm} \mathrm{Hg}$. Precautions were taken not to depress the syringe plunger too rapidly or placing the needle into the tendon, as these may give a false high reading. A new needle was used for each measurement in order to assure accuracy.

The whole procedure is repeated for the other compartments also. The values are entered in the proforma. Cases showing high pressure (i.e. where the difference between the diastolic blood pressure and compartment were less than $30 \mathrm{mmHg}$ ) were subjected to further assessment of arterial blood flow by Doppler studies and the arterial insufficiency if any was confirmed. They were immediately subjected to decompression of the affected osteo-fascial compartment by single or double incision methods. Others showing normal or slightly elevated pressure were given a long leg plaster of Paris slab after manipulative reduction and the readings were repeated after 4 to 6 hours. Those cases which showed normal or only mild elevation of compartment pressure after 48 hours of injury were considered not at risk and they were treated either by 
immobilization in a cast or interlocking intramedullary nail depending on the morphology of fracture.

Those cases which showed moderate elevation of compartment pressure at initial assessment and further increase in subsequent measurements were observed closely. Those showing evidence of vascular impediments by Doppler studies and physical findings within 36 hours were subjected to fasciotomy. Cases showing moderate elevation of pressure without definite evidence of vascular impediments were retained under observation till the swelling of the limb and the tenseness on palpation subsided and then put on plaster of Paris cast or internally fixed.

Normal values for each compartment were assessed by measuring the uninjured limbs of normal persons of age ranging from 9-75 years and of both sexes. Readings were taken as per the technique described earlier.

The normal range of values for the various compartments was obtained as follows:

i)anterior compartment- $10-14 \mathrm{~mm} \mathrm{Hg}$; ii) peroneal compartment- $8-10 \mathrm{~mm} \mathrm{Hg}$; iii) deep posterior compartment- 8-12 $\mathrm{mm} \mathrm{Hg}$; iv) superficial posterior compartment- $8-10 \mathrm{~mm} \mathrm{Hg}$. Age and sex of the patient did not affect the compartment pressure. The position of the limb causes variation of the compartment pressure up to $4-6 \mathrm{~mm} \mathrm{Hg}$.

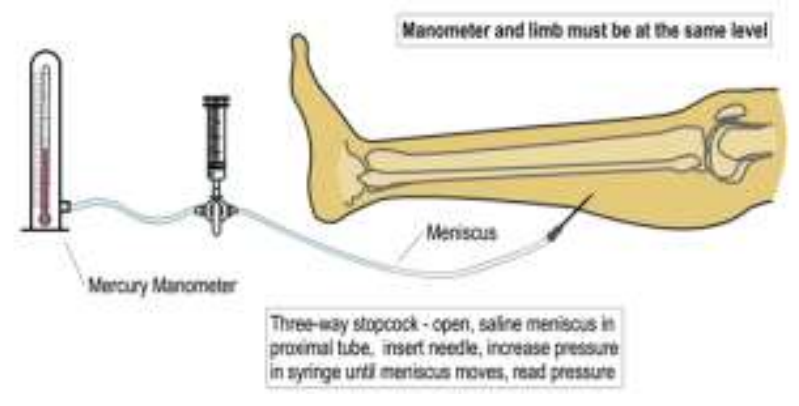

Figure 1: Compartment measurement set up in Whitesides' technique.

\section{RESULTS}

The present study included 24 patients with affected 25 limbs. All were closed fractures of tibia due to road accidents admitted to the casualty within 12 hours of injury. Out of the 24 patents studied majority were males. 20 patients were males and the rest females. Youngest patient in the study group was a 9 year old boy and the oldest was 74 year old gentleman. Majority of the male patients fall in the age group of 31-45 years. 3 out of 4 females belonged to the $46-60$ years age group as given in Table 1.

Most of the cases were with tibial fractures. 15 out of 25 limbs were with lower third fractures $(60 \%)$ followed by upper third $6(24 \%)$ and middle third $4(16 \%)$ as presented in Figure 2. Out of 25 limbs 20 cases $(80 \%)$ had associated fracture of fibula and $5(20 \%)$ were not associated with it as given in Figure 3.

Table 1: Distribution of patients according to sex and age groups.

\begin{tabular}{|llllll|}
\hline \multirow{5}{*}{ Sex } & Age & & & & \\
& $9-15$ & $16-30$ & $31-45$ & $46-60$ & $61-75$ \\
& years & years & years & years & years \\
\hline Male & 2 & 3 & 9 & 2 & 4 \\
\hline Female & 0 & & & 3 & 1 \\
\hline
\end{tabular}

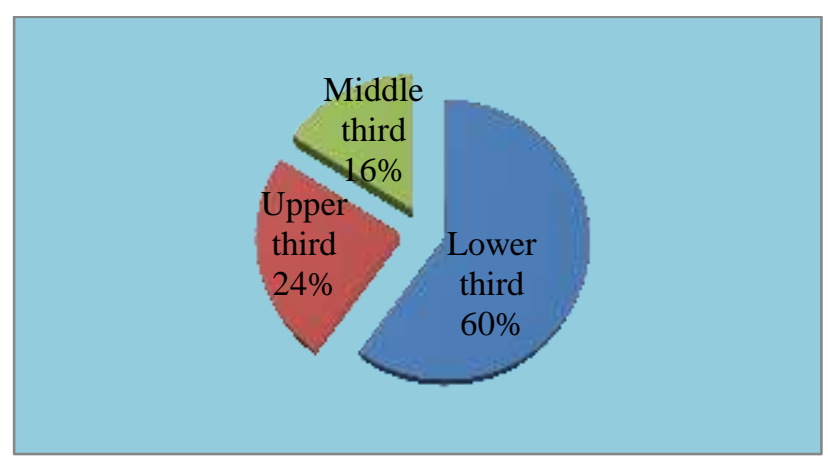

Figure 2: Level of tibial fracture.

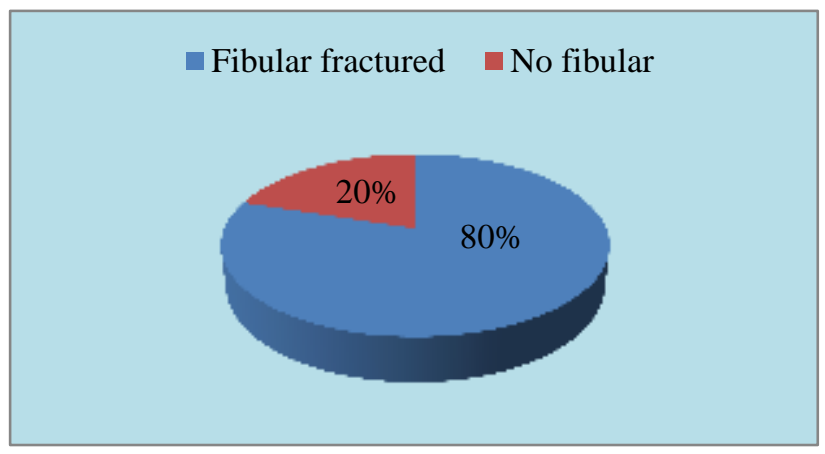

Figure 3: Percentage of fibular cases.

In about $32 \%$ of fractures of tibia there is an initial increase in the compartment pressure. In majority of cases the pressure came to normal level within 36-48 hours. Cases which showed compartment pressure above $50 \mathrm{~mm} \mathrm{Hg}$ showed definite evidence of arterial impediment as proved by Doppler studies. The percentage of cases with raised compartmental pressure was given in Figure 4.The upper third fractures are more prone to develop compartment syndrome than others. Out of six cases of upper third fractures, three developed high pressure and were subjected to fasciotomy. Out of the four middle third fractures, one required fasciotomy and out of the fifteen lower third fractures none showed significant high pressure and none required fasciotomy as presented in Figure 5. 


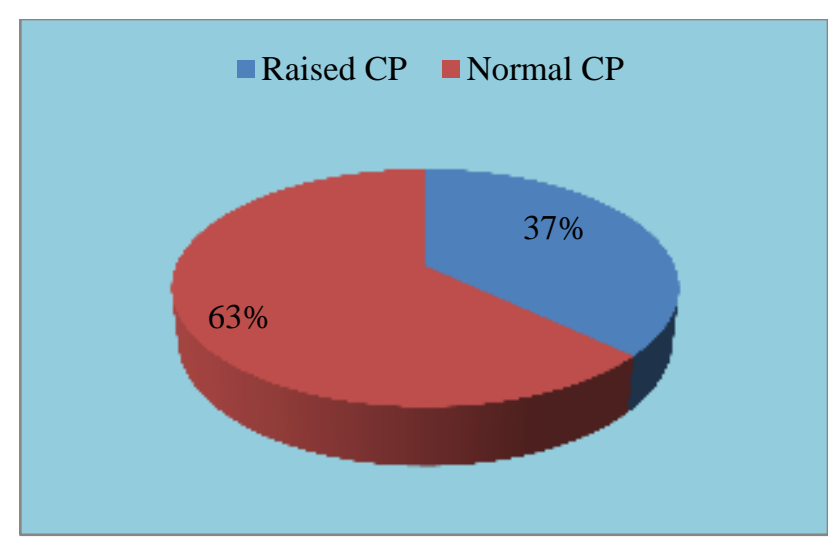

Figure 4: Percentage increase in compartmental pressure.

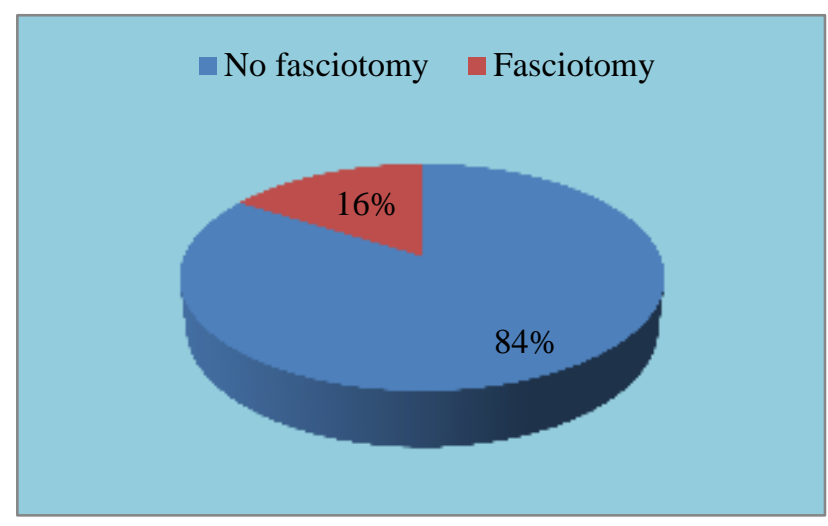

Figure 5: Percentage of cases required fasciotomy.

\section{DISCUSSION}

Ischaemic contractures and deformities of leg and foot are well known complications of fractures of tibia. Severe ischemic contractures develops compartment syndrome due to increased pressure at damaged site and results in muscle and nerve ischemia.

Compartment pressure measurement is the most reliable and objective method for early diagnosis. A number of methods are now available for monitoring the compartment pressure. ${ }^{9}$ Stryker hand held monitor, Slit catheter, Wick catheter, fibreoptic transducer and ultrasound scanning to measure exercise ischemia. ${ }^{10-14}$ Whitesides technique is one of the simple and effective method to measure compartment pressure as the equipment was easy to set up, safe and reproducible with chances of less errors. $^{15,16}$

In the normal limbs studied the compartment pressure ranged from 8-14 $\mathrm{mm} \mathrm{Hg}$ from the anterior to deep posterior compartments showing a little higher value than the other two. In the present study, out of the 25 limbs studied, 17 showed normal range of compartment pressure at the time of admission and showed negligible variation in subsequent readings. Such cases include all ages and both sexes. Strikingly, none of them had skin bruising, soft tissue contusions or swelling of the limbs. Fifteen out of these were lower third fractures. Twenty of them had associated fracture of fibula.

In our study the criteria of differential pressure of less than $30 \mathrm{~mm}$ of $\mathrm{Hg}$ was used for the diagnosis of compartment syndrome and fasciotomy, which was used by McQueen et al and Mubarak et al.,12 Heckman et al have used the criteria of differential pressure of less than $20 \mathrm{~mm}$ of $\mathrm{Hg}$ for the diagnosis of compartment syndrome and they advocated fasciotomy. ${ }^{17}$

In this study out of $32 \%$ cases with increased compartment pressure, one case with upper third fracture and associated fracture of fibula showed very high compartment pressure (i.e. value above $45 \mathrm{~mm} \mathrm{Hg}$ ) in the first reading itself and these were correlated with other clinical features and confirmed by Doppler study and immediate fasciotomy was done. 7 cases showed moderate increase $(20-30 \mathrm{~mm} \mathrm{Hg})$ in compartment pressure initially, were observed closely by clinical examination and frequent measurement of compartment pressure. One of these cases with middle third fracture and associated fracture of fibula with mild swelling of the limb showed remarkable shoot up during the second reading and this was subjected to immediate fasciotomy. The remaining six showed decrease in pressure in the subsequent observation, and were treated conservatively for the fracture. During the observation period of first 48 hours the splinted limbs were kept at the level of the body, without elevating the foot end of the bed, to facilitate maximum arterial flow. Active toe movements were encouraged. Once the observation is over, the position of the fragments is reassessed radiologically, manipulated if needed and immobilized in plaster of Paris cast or internally fixed with interlocking intramedullary nail.

Cases which underwent fasciotomy and those which passed the critical period were advised to keep the foot end of the bed elevated in order to facilitate venous return. In subsequent follow up after three months none of the above cases showed any features of ischaemic contractures or any neurological deficits.

\section{CONCLUSION}

Compartment pressure measurement is a very good index for predicting and preventing compartment syndrome. Early diagnosis can minimize the soft tissue damage and therefore improve the long-term results. Whitesides' technique, though not much widely favoured but it is a safe, effective, easily assembled, reliable and method for measurement of intracompartmental pressure in a peripheral setup in developing countries.

Funding: No funding sources Conflict of interest: None declared

Ethical approval: The study was approved by the institutional ethics committee 


\section{REFERENCES}

1. Pettitt DA, McArthur P. Clinical review: Volkmann's ischaemic contracture. European Journal of Trauma and Emergency Surgery. 2012;38(2):129-37.

2. DeLee JC, Stiehl JB. Open tibia fracture with compartment syndrome. Clin Orthop Relat Res. 1981;160:175-84.

3. McQueen MM, Christie J, Court-Brown CM. Acute compartment syndrome in tibial diaphyseal fractures. J Bone Joint Surg Br. 1996;78(1):95-8.

4. Blick SS, Brumback RJ, Poka A, Burgess AR, Ebraheim NA. Compartment syndrome in open tibial fractures. J Bone Joint Surg Am. 1986;68(9):1348-53.

5. Frink M, Hildebrand F, Krettek C, Brand J, Hankemeier S. Compartment Syndrome of the Lower Leg and Foot. Clin Orthop Relat Res. 2010;468(4):940-50.

6. DeLee JC, Stiehl JB. Open tibia fracture with compartment syndrome. Clin Orthop Relat Res. 1981;160:175-84.

7. Whitesides TE Jr, Haney TC, Harada H, Holmes HE, Morimoto K. A simple method for tissue pressure determination. Arch Surg. 1975;110:13113.

8. Al Dadah OQ, Darrah C, Cooper A, Donell ST, Patel AD. Continuous compartment pressure monitoring vs. clinical monitoring in tibial diaphyseal fractures. Injury. 2008;39:1204-9.

9. Brostrom LA, Stark A, Svartengren G. Acute compartment syndrome in forearm fractures. Acta Orthop Scand. 1990;61:50-3.

10. Uppal GS, Smith RC, Sherk HH, Mooar P. Accurate compartment pressure measurement using the Intervenous Alarm Control (IVAC) Pump:
Report of a technique. J Orthop Trauma 1992;6(1):87-9.

11. Rorabeck CH, Castle GSP, Hardic R, Logan L. Compartmental Pressure Measurements- An Experimental Investigation Using the Slit Catheter. Journal Of Trauma. 1981;21(6)446-9.

12. Mubarak SJ, Owen CA, Hargens AR, Garetto LP, Akeson WH. Acute compartment syndromes: diagnosis and treat- ment with the aid of the wick catheter. J Bone Joint Surg [Am]. 1978;60:1091-5.

13. Willy C, Gerngross H, Sterk J. Measurement of intracompartmental pressure with use of a new electronic transducer-tipped catheter system. J. Bone Joint Surg. Am. 1999;81(2):158-68.

14. Gershuni DH, Gosnik BB, Hargens AR, Gould RN, Forsythe RD, Mubarack SJ, Akesan WH. Ultrasound Evaluation of the Anterior Musculofascial Compartment of Leg Following Exercise. CORR. 1982;167:185-90.

15. Sangwan SS, Marya KM, Devgan A, Siwach RC, Kundu JS, Gupta PK. Critical evaluation of compartment pressure measurement by saline manometer in peripheral hospital set up. Trop Doct. 2003;33:100-3.

16. Ogunlusi JD, Oginni LM, Ikem IC. Compartmental pressure in adults in tibial fractures. Int Orthop. 2005;29:130-3.

17. Heckman MM, Whitesides TE, Grewe Sr, Rooks MD. Compartment pressure in association with closed tibial fractures. The relationship between tissue pressure, compartment and the distance from the site of the fracture. J Bone Joint Surg Am. 1994;76:1285-92.

Cite this article as: Pillai MG. Compartment pressure changes after closed fractures of tibia. Int J Res Orthop 2016;2:189-93. 